\title{
Abrupt thermal transition reveals hydrothermal boundary and role of seamounts within the Cocos Plate
}

\author{
A. T. Fisher, ${ }^{1}$ C. A. Stein,${ }^{2}$ R. N. Harris,${ }^{3}$ K. Wang, ${ }^{4}$ E. A. Silver, ${ }^{1}$ M. Pfender, ${ }^{5}$ \\ M. Hutnak, ${ }^{1}$ A. Cherkaoui, ${ }^{1}$ R. Bodzin, ${ }^{1}$ and H. Villinger ${ }^{5}$ \\ Received 13 December 2002; revised 26 March 2003; accepted 11 April 2003; published 3 June 2003.
}

[1] New thermal data from 18-24 Ma lithosphere on the Cocos Plate delineate contrasting subsurface thermal conditions in adjacent sections of crust. Heat flow through seafloor created at the East Pacific Rise is generally suppressed by $\sim 70 \%$ relative to conductive lithospheric cooling models, whereas heat flow through adjacent, similarly-aged lithosphere generated at the Cocos-Nazca Spreading Center is consistent with these models. The transition between thermal regimes is remarkably abrupt, only $2-5 \mathrm{~km}$ wide, indicating a shallow hydrothermal origin. The transition is more closely associated with differences in the distribution of basement outcrops than with tectonic boundaries, demonstrating the importance of the former in extracting heat from the lithosphere on a regional basis. INDEX TERMS: 3015 Marine Geology and Geophysics: Heat flow (benthic) and hydrothermal processes. Citation: Fisher, A. T., C. A. Stein, R. N. Harris, K. Wang, E. A. Silver, M. Pfender, M. Hutnak, A. Cherkaoui, R. Bodzin, and H. Villinger, Abrupt thermal transition reveals hydrothermal boundary and role of seamounts within the Cocos Plate, Geophys. Res. Lett., 30(11), 1550, doi:10.1029/2002GL016766, 2003.

\section{Introduction}

[2] The thermal state of subducting plates influences the location of the seismogenic zone and the magnitude of earthquakes, the extent of diagenesis during subduction, and the structure and hydrogeology of subducting and overlying sediments and rocks [Hyndman and Wang, 1993; Peacock and Wang, 1999; Shipley et al., 1990]. We completed seismic, swath-mapping, and heat flow surveys of 18-24 Ma seafloor offshore of the Nicoya Peninsula, Costa Rica margin (TicoFlux program), to assess the thermal state of the Cocos Plate seaward of the Middle America Trench (MAT; Figure 1). The Cocos Plate has a complex tectonic history in this region [Barckhousen et al., 2001; Hey, 1997; Meschede et al., 1998; von Huene et al., 2000], and comprises seafloor generated at the fast-spreading East Pacific Rise (EPR) and the medium-spreading Cocos-Nazca \footnotetext{
USA.

${ }^{1}$ Earth Sciences Department, University of California, Santa Cruz, CA,

${ }^{2}$ Department of Earth and Environmental Sciences, University of Illinois at Chicago, Chicago, IL, USA.

${ }^{3}$ Department of Geology and Geophysics, University of Utah, Salt Lake City, UT, USA.

${ }^{4}$ Pacific Geoscience Center, Geological Survey of Canada, Sydney, BC, Canada.

${ }^{5}$ Department of Earth Science, University of Bremen, Bremen, Germany.
}

Copyright 2003 by the American Geophysical Union. 0094-8276/03/2002GL016766\$05.00
Spreading Center (CNS). A triple junction trace and fracture zone collectively define a plate "suture" between crust generated at the EPR and that formed at the CNS (Figure 1).

[3] Conductive lithospheric cooling models predict heat flow of $95-120 \mathrm{~mW} / \mathrm{m}^{2}$ for 18-24 Ma seafloor [Parsons and Sclater, 1977; Stein and Stein, 1994]. Prior to our survey, widely-spaced heat flow measurements in this area suggested that a large region of EPR-generated seafloor was unusually cool, whereas values on CNS-generated seafloor were scattered but had a mean value close to conductive predictions [Vacquier et al., 1967; Von Herzen and Uyeda, 1963]. New data were required to find the location of the transition in lithospheric thermal state, determine whether it is associated one or more of the regional tectonic boundaries, and evaluate its width and cause.

[4] The TicoFlux program included collection of multichannel seismic and swath-map data, heat flow measurements, and gravity and piston cores. Seismic lines were positioned to cross tectonic boundaries in several places, and to provide data both parallel to and perpendicular to isochrons on either side of the plate suture. Heat flow was measured along transects co-located with seismic data so that sediment thickness and basement structure could be correlated with thermal conditions.

\section{Results and Analyses}

[5] New data demonstrate that EPR-generated seafloor approaching the MAT in this area is anomalously cool on a regional basis, with heat flow values of $20-40 \mathrm{~mW} / \mathrm{m}^{2}$, only $\sim 30 \%$ of that predicted by conductive lithospheric cooling models (Figure 1B). In contrast, CNS-generated seafloor yielded heat flow values of $105-115 \mathrm{~mW} / \mathrm{m}^{2}$, consistent with conductive models. Mean values on both sides of the transition are anomalous relative to the global measured mean for 18-24 Ma lithosphere, $60-80 \mathrm{~mW} / \mathrm{m}^{2}$ [e.g., Stein and Stein, 1994].

[6] We crossed the thermal transition along four heat flow transects during the regional survey (Figure 1B; HF-01, HF08, HF-10, HF-12). The change from anomalously-low to anomalously-high heat flow occurred across a lateral distance of $\leq 5 \mathrm{~km}$ in all cases, with most of the transition occuring between adjacent measurements $<2 \mathrm{~km}$ apart (Figure 2). The thermal transition along transects HF-01, HF-10, and HF-12 is offset to the northwest of the plate suture by 31,41 , and $35 \mathrm{~km}$, respectively (Figure 1B). The transition along transect HF-08 coincides approximately with the plate suture (Figure 1B), as defined by magnetic anomalies [Barckhousen et al., 2001; Meschede et al., 1998; von Huene et al., 2000] and the difference in basement depth on either side of the boundary (100-150 m; Figure 2A). 

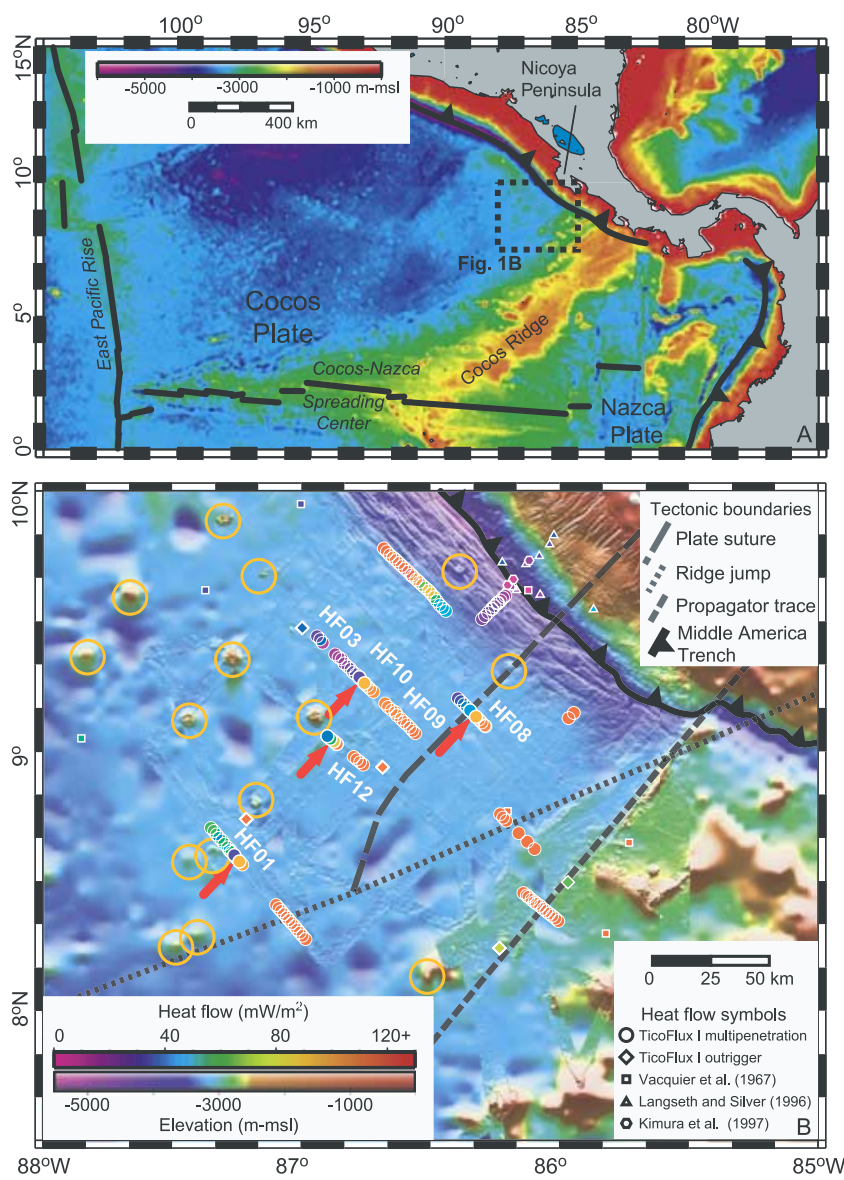

Figure 1. Maps of field area. A. Regional map showing spreading centers and bathymetry [Smith and Sandwell, 1997]. Dashed box indicates field area in Figure 1B. B. Seafloor bathymetry based on satellite gravimetry and swath mapping [new data, Barckhousen et al., 2001; von Huene et al., 2000]; tectonic boundaries from bathymetry, gravity, and magnetics [Barckhousen et al., 2001; Hey, 1977; Meschede et al., 1998]. Color-coded symbols are heat flow values [circles and diamonds: this study; other sources as labeled]. Red arrows indicate abrupt thermal transitions separating areas of anomalously low heat flow from areas with elevated heat flow. Note large basement outcrops (gold circles) typically spaced $20-50 \mathrm{~km}$ apart, on EPR-generated seafloor north of the plate suture, but not on CNS-generated seafloor south of the suture and north of the ridge jump. Smaller outcrops on EPR-generated seafloor are not apparent at this scale.

[7] The abruptness of the thermal transition indicates that it results from shallow processes in the crust. To estimate the depth to the "source" of the thermal transition, we used a two-dimensional numerical model of conductive heat transport [Zyvoloski et al., 1996]. Rectangular model grids were $100 \mathrm{~km}$ wide and $40 \mathrm{~km}$ thick, intended to represent the upper lithosphere, including $375 \mathrm{~m}$ of marine sediments overlying basement rocks, each having appropriate thermal properties. Heat was input evenly at the base of the domain and $70 \%$ of this heat was extracted within the left half of the domain by point sinks distributed at various depths. These point sinks represent advective heat loss associated with hydrothermal flow, but do not specify flow paths or fluid fluxes. We compared model output to field observations to find the depth of heat extraction that results in seafloor thermal transitions having observed widths.

[8] Comparison between observations and modeling results (Figure 3) indicates that the depth to the top of the region of advective heat extraction within EPR-generated seafloor is no more than $100-600 \mathrm{~m}$ into basement. We also analyzed plate flexure perpendicular to the trench and differences in basement depths across the plate suture. The effective elastic thickness of the plate $(\sim 11 \mathrm{~km})$ is consistent with normal thermal conditions within 18-24 m.y.-old seafloor [Wessel, 1992]. Small differences in basement depth across the plate suture also preclude large differences in thermal structure below the crust. Thus we conclude that shallow hydrothermal circulation in the upper basement suppresses seafloor heat flow from the Cocos Plate seaward of the MAT in crust generated along the EPR. In contrast, there is little advective heat loss from adjacent, similarly aged crust formed at the CNS.

\section{Discussion}

[9] Why does hydrothermal circulation extract so much heat from EPR-generated seafloor on one site of the plate suture, and so little heat from adjacent, CNS-generated seafloor of a similar age on the same plate? We consider three possible explanations, the last being the most likely.

[10] 1) Normal faulting associated with flexure at the outer slope of the MAT increases permeability, fluid circulation, and advective heat loss within EPR-generated seafloor. The difficulty with this explanation is that the region of low heat flow extends at least $1,000 \mathrm{~km}$ from MAT, including the other side of the EPR [Baker et al., 1991;

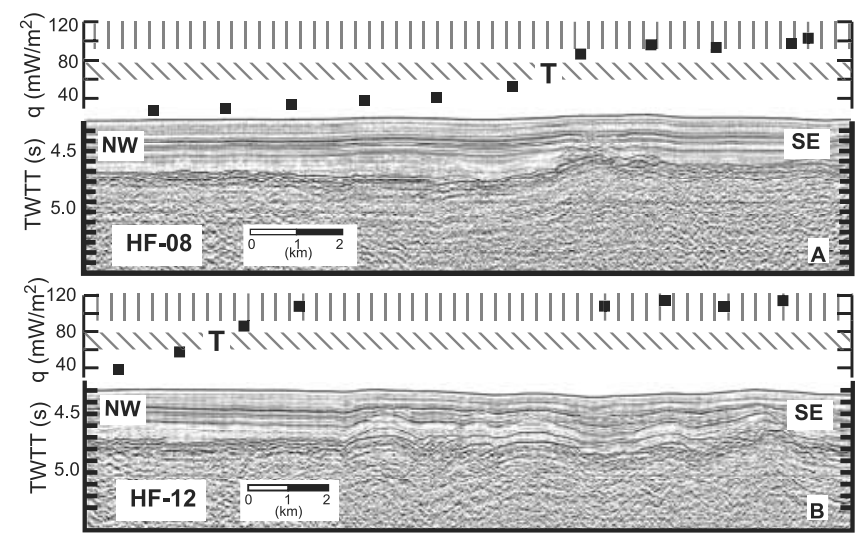

Figure 2. Example thermal transitions. A. Seismic and heat flow data along HF-08 (Figure 1B). Band of vertical lines shows conductive prediction for heat flow through 18-24 Ma seafloor; diagonal lines show observed global mean $. \mathrm{T}=$ approximate thermal transition location; $\mathrm{TWTT}=$ two-way travel time. This thermal transition coincides approximately with the plate suture. C. Seismic and heat flow data along HF-12 (Figure 1B). This thermal transition is located $35 \mathrm{~km}$ northwest of the plate suture and is not associated with any structure in basement. The other thermal transitions are also offset greatly from the plate suture and are equally abrupt. 


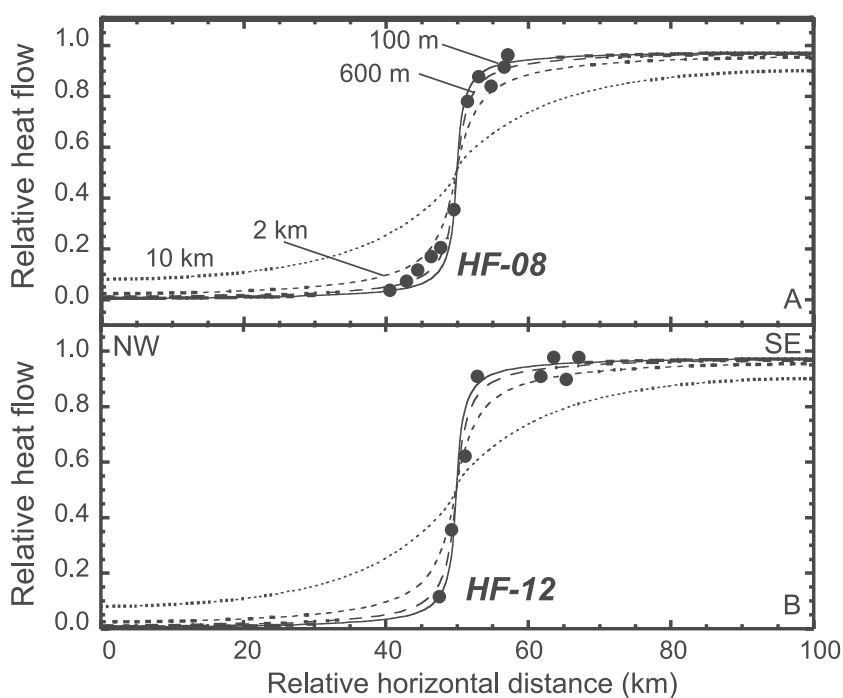

Figure 3. Comparison of observations from thermal transitions (circles) and modeling results (lines). Heat sinks were distributed at various depths below top of basement (as indicated). Model results and observations normalized on a scale of 0 to 1 , representing $30 \%$ of lithospheric heat flow and $100 \%$ of lithospheric heat flow, respectively, based on local values away from the transition. A. Heat flow station HF-08. B. Heat flow station HF-12.

Stein and Stein, 1994]. In contrast, extensive normal faulting in the TicoFlux area develops mainly within 50$75 \mathrm{~km}$ of the trench, based on swath map and seismic data, consistent with observations near other trenches [Masson, 1991]. In addition, normal faults near the trench in the TicoFlux region (a) are covered by $300-400 \mathrm{~m}$ of poorly lithified sediments, and (b) have offsets that are insufficient to expose basement, and thus do not provide open conduits for rapid hydrothermal exchange. Normal faulting may contribute to low heat flow measured in the trench [Kimura et al., 1997; Langseth and Silver, 1996], through locallyenhanced permeability and circulation, but can not explain the regional pattern.

[11] 2) Heat flow is higher on CNS-generated crust because passage over the Galapagos hot spot added heat to this part of the plate, compensating for earlier cooling. Heat flow around hot spots generally deviates little (less than $5-10 \mathrm{~mW} / \mathrm{m}^{2}$ ) from that through similarly aged seafloor far from hot spots [e.g., Stein and Stein, 1993; von Herzen et al., 1989]. CNS-generated seafloor in the TicoFlux area passed over the hot spot millions of years ago, so the residual thermal influence is minimal. In addition, the close match between observed and conductive heat flow on CNS-generated crust would require a remarkable coincidence, that reheating exactly offsets earlier hydrothermal cooling. Finally, such reheating can not explain why heat flow through EPR-generated seafloor is $\sim 70 \%$ lower than that predicted by conductive models.

[12] 3) Basement outcrops common on EPR-generated seafloor in our area, but absent on CNS-generated seafloor immediately south of the plate suture (Figure 1B), provide pathways for recharge and discharge of hydrothermal fluids. The forces available to drive hydrothermal circulation on ridge flanks are modest, being limited mainly to pressure differences at the base of recharging and discharging columns of water [e.g., Fisher and Becker, 2000; Giambalvo et al., 2000]. These forces are insufficient by several orders of magnitude to move fluids at thermallysignificant rates through $300-400 \mathrm{~m}$ of calcareous and hemipelagic sediments. Basement outcrops allow hydrothermal fluids to bypass the sediment column and extract lithospheric heat efficiently [e.g., Fisher et al., 2003; Villinger et al., 2002]. Three of four crossings of the thermal transition are closer to basement outcrops than to tectonic boundaries (HF-01, HF-08, HF-12). The fourth (HF-10), coincides with the plate suture but is also close to a basement outcrop (Figure 1B). Basement outcrops are noticeably absent on CNS-generated seafloor near the MAT and adjacent to the plate suture, where seafloor heat flow matches conductive predictions (Figure 1B).

[13] There is one difficulty with this explanation: seamounts and basement outcrops are common features on a global basis [e.g., Wessel, 2001], but EPR-generated seafloor in the TicoFlux area is unusually cool compared to the mean for crust of this age. Basement outcrops facilitate the efficient exchange of fluids, heat, and solutes between crust and ocean, but heat transport in basement between outcrops will be dominated by conduction unless there are well-developed pathways allowing rapid fluid flow and mixing. Hydrothermal circulation through EPR-generated seafloor in the TicoFlux area must be particularly vigorous far from outcrops, and this requires anomalously high driving forces and/or high basement permeability. Hydrothermal driving forces on ridge flanks are especially limited where cooling is efficient, since this reduces the temperature differences between recharging and discharging water columns. Thus we hypothesize that lateral permeability in basement is exceptionally high in this area.

[14] Crustal construction at the EPR may favor elevated basement permeability in the TicoFlux area. Fast spreading centers tend to be more magmatically robust than moderate to slow spreading centers, resulting in a higher ratio of sheet flows to pillows, and a relatively lower influence of tectonic extension [e.g., Karson, 2002; Perfit and Chadwick, 1998; Wilcock and Delaney, 1996]. Off-axis magmatic and tectonic activity associated with formation of the Cocos Ridge on CNS-generated seafloor in the TicoFlux area may have led to additional hydrogeologic "compartmentalization" of basement rocks through intrusions and high-angle faulting, reducing lateral connectivity within basement. This would limit large-scale advective heat extraction from CNSgenerated seafloor in this area, even if there is high permeability on a local basis. This hypothesized difference in basement properties can be tested through direct measurement.

\section{Conclusions}

[15] We find a remarkably abrupt thermal transition between parts of a lithospheric plate of a similar age produced at different spreading centers, which requires an extreme contrast in the nature and extent of hydrothermal circulation in shallow basement. This circulation is facilitated on the cool side of the transition by seamounts and basaltic outcrops separated by tens of kilometers, allowing recharging and discharging fluids to bypass the sediment 
column and advectively extract $\sim 70 \%$ of lithospheric heat over a large area. This circulation system was active long before the plate came under the influence of the adjacent trench. Although the length scales of flow between outcrops in this area are similar to that seen on another ridge flank [Fisher et al., 2003], the circulation system on the cool side of the Cocos Plate is unusually efficient in extracting lithospheric heat on a regional basis, suggesting that basement permeability may be especially high.

[16] Acknowledgments. We thank the officers, crew, and technicians of $\mathrm{R} / \mathrm{V}$ Maurice Ewing for their assistance and advice during the regional TicoFlux expedition. C. Ranero provided a compilation of earlier bathymetric data. R. Cleary provided field assistance. This work was supported by NSF OCE-0001892, OCE-0001941, and OCE-0001944 (UU); CULAR project STB-UC98-181; and IGPP/LANL project 1317. Comments from two reviewers improved this manuscript.

\section{References}

Baker, P., P. Stout, M. Kastner, and H. Elderfield, Large-scale lateral advection of seawater through oceanic crust in the central equatorial Pacific, Earth. Planet. Sci. Lett., 105, 522-533, 1991.

Barckhousen, U., C. Renaro, R. von Huene, S. C. Cande, and H. A. Roeser, Revised tectonic boundaries in the Cocos Plate off Costa Rica: implications for the segmentation of the convergent margin and for plate tectonic models, J. Geophys. Res., 106(B9), 19,207-19,220, 2001.

Fisher, A., and K. Becker, Channelized fluid flow in oceanic crust reconciles heat-flow and permeability data, Nature, 403, 71-74, 2000.

Fisher, A. T., E. E. Davis, M. Hutnak, V. Spiess, L. Zühlsdorff, A. Cherkaoui, L. Christiansen, K. M. Edwards, R. Macdonald, H. Villinger, M. J. Mottl, C. G. Wheat, and K. Becker, Hydrothermal recharge and discharge across $50 \mathrm{~km}$ guided by seamounts on a young ridge flank, Nature, 421, $618-621,2003$.

Giambalvo, E., A. T. Fisher, L. Darty, J. T. Martin, and R. P. Lowell, Origin of elevated sediment permeability in a hydrothermal seepage zone, eastern flank of Juan de Fuca Ridge, and implications for transport of fluid and heat, J. Geophys. Res., 105(B1), 913-928, 2000.

Hey, R. N., Tectonic evolution of the Cocos. Nazia Spreading Center, Geol. Soc. Am. Bull., 88, 1404-1420, 1977.

Hyndman, R. D., and K. Wang, Thermal constraints on the seismogenic portion of the southwestern Japan subduction zone of subduction thrust faults, J. Geophys. Res., 100, 2039-2060, 1993.

Karson, J. A., Geologic structure of the uppermost oceanic crust created at fast- to intermediate-rate spreading centers, Ann. Rev. Earth Planet. Sci., 30, 347-384, 2002.

Kimura, G., E. Silver, and P. Blum, Proceedings of the Ocean Drilling Program, Initial Reports, pp. 458, Ocean Drilling Program, College Station, TX, 1997.

Langseth, M. G., and E. A. Silver, The Nicoya convergent margin - a region of exceptionally low heat flow, Geophys. Res. Lett., 23(8), 891-894, 1996.

Masson, D. G., Fault patterns at outer trench walls, Mar. Geophys. Res., 13, 209-225, 1991.

Meschede, M., U. Barckhausen, and H.-U. Worm, Extinct spreading on the Cocos Ridge, Terra Nova, 10, 211-216, 1998.

Parsons, B., and J. G. Sclater, An analysis of the variation of ocean floor bathymetry and heat flow with age, J. Geophys. Res., 82, 803-829, 1977.
Peacock, S. M., and K. Wang, Seismic consequences of warm versus cool subduction metamorphism: examples for southwest and northeast Japan, Science, 286, 937-939, 1999.

Perfit, M. R., and W. W. Chadwick Jr., Magmatism at mid-ocean ridges: constraints from volcanological and geochemical investigations, in Faulting and magmatism at mid-ocean ridges, edited by W. R. Buck, P. T. Delaney, J. A. Karson, and Y. Lagabrielle, pp. 59-115, American Geophysical Union, Washington, DC, 1998.

Shipley, T.-H., P. L. Stoffa, and D. F. Dean, Underthrust sediments, fluid migration paths, and mud volcanoes associated with the accretionary wedge off Costa Rica: Middle America Trench, J. Geophys. Res., 95, 8743-8752, 1990.

Smith, W. H. F., and D. T. Sandwell, Global sea floor topography from satellite altymetry and ship depth soundings, Science, 277, 1956-1962, 1997.

Stein, C., and S. Stein, Constraints on hydrothermal heat flux through the oceanic lithosphere from global heat flow, J. Geophys. Res., 99, $3081-$ 3095, 1994.

Stein, C. A. and S. Stein, Constraints on Pacific midplate swells from global depth-age and heat flow -age models, in The Mesozoic Pacific, edited by M. Pringle, W. W. Sager, W. Sliter, and S. Stein, pp. 53-76, American Geophysical Union, Washington, D. C., 1993.

Vacquier, V., J. G. Sclater, and C. E. Corry, Studies in the thermal state of the earth, the 21 st paper: heat-flow, Eastern Pacific, Bulletin of the Earthquake Research Institute, 45, 375-393, 1967.

Villinger, H., I. Grevemeyer, N. Kaul, J. Hauschild, and M. Pfender, Hydrothermal heat flux through aged oceanic crust: where does the heat escape?, Earth. Planet. Sci. Lett., 202(1), 159-170, 2002.

Von Herzen, R., and S. Uyeda, Heat flow through the eastern Pacific floor, J. Geophys. Res., 68, 4219-4250, 1963.

von Herzen, R. P., M. J. Cordley, R. S. Detrick, and C. Fang, Heat flow and the thermal origin of hot spot swells: the Hawaiian swell revisited, J. Geophys. Res., 94, 13,783-13,799, 1989.

von Huene, R., C. R. Ranero, W. Wienrebe, and K. Hinz, Quarternary convergent margin tectonics of Costa Rica, segmentation of the Cocos Plate, and Central American Volcanism, Tectonics, 9(2), 314-334, 2000 .

Wessel, P., Thermal stresses and the bimodal distribution of elastic thickness estimates of the oceanic lithosphere, J. Geophys. Res., 97(10), 14,177-14,193, 1992.

Wessel, P., Global distribution of seamounts inferred from gridded Geosat/ ERS-1 altimetry, J. Geophys. Res., 106(B9), 19,431-19,442, 2001.

Wilcock, W. S. D., and J. R. Delaney, Mid-ocean ridge sulfide deposits: evidence for heat extraction from magma chambers or cracking fronts, Earth. Planet. Sci. Lett., 145, 49-64, 1996.

Zyvoloski, G. A., B. A. Robinson, Z. D. Dash, and L. L. Trease, Users manual for the FEHMN application, Los Alamos National Laboratory, Los Alamos, 1996.

A. T. Fisher, E. A. Silver, M. Hutnak, A. Cherkaoui, and R. Bodzin, Earth Sciences Department, University of California, Santa Cruz, CA, USA.

C. A. Stein, Department of Earth and Environmental Sciences, University of Illinois at Chicago, Chicago, IL, USA.

R. N. Harris, Department of Geology and Geophysics, University of Utah, Salt Lake City, UT, USA.

K. Wang, Pacific Geoscience Center, Geological Survey of Canada, Sydney, BC, Canada.

M. Pfender and H. Villinger, Department of Earth Science, University of Bremen, Bremen, Germany. 